\title{
Editorial: introducing Learning Inquiry
}

\author{
Jason Nolan · Jeremy Hunsinger
}

Received: 12 January 2007/ Accepted: 17 January 2007/ Published online: 8 March 2007

(C) Springer Science+Business Media, LLC 2007

The impetus for the development of Learning Inquiry was a consequence of the development of courses on learning in non-school settings by Joel Weiss. As far back as the late 1990s, Joel recognized the need for a reference work on learning that cut across different academic fields and all facets of our lives. With Jason Nolan, he initiated the planning of an Encyclopedia of Learning that culminated in organizing a meeting of learning scholars in October 2004 held at Maxine Greene's apartment overlooking Central Park in NYC. The scholars present were Joel, David Berliner, Erik De Corte, Katie Embree, Maxine Greene, Heinz Mandl, Roy Pea, Jeremy Hunsinger, Jason. At the meeting Roy suggested that a journal should be developed with a transdisciplinary approach that addressed different facets of learning: human, non-human, and the systems in which they exist. Since Joel had been the founding editor of the journal Curriculum Inquiry, it was thought that an appropriate, complementary title would be Learning Inquiry.

The consensus was that the journal should engage a wide audience as well as include every field that took up inquiry into learning in any form whatsoever. Yet at the same time we wanted to maintain a level of scholarship and intellectual rigor so that the journal and the contents are taken seriously. The next step was a strange twist of fate. It was Roy who again suggested that this was perhaps not a job for scholars with long standing in specific fields, but rather for younger academics working with more fluid boundaries of emerging domains of knowledge with less clearly defined restrictions; those being Jeremy and Jason.

We submitted a formal proposal to Springer that, after some back and forth discussions, was finally accepted. With Springer being willing to support the development and publication of the journal, it was clear that the journal that came to be called Learning Inquiry would have the level of support to reach a wide audience, so

J. Nolan $(\bowtie)$

School of Early Childhood Education, Ryerson University, KHS 348-E, 350 Victoria St.,

Toronto, ON, Canada 5B 2K3

e-mail: editors@learning-inquiry.info

J. Hunsinger

School of Information and Library Science, Pratt Institute, New York, USA 
there was no question of our willingness to accept this opportunity. We want to thank Springer for helping us to establish Learning Inquiry and for their continued support.

Though the road from that meeting to this first issue in 2007 has been long, we have not been idle. The first step was to establish our aims and scope, and gather an Editorial Board that would reflect our hopes for the journal. Our core board members came from that initial meeting: David Berliner from Arizona State University, Erik De Corte of the Catholic University of Leuven, Kattie Embree from Columbia University, and Joel Weiss, University of Toronto. In order to increase our breadth we sent out some invitations and were able to round out our Editorial Board with a wonderful group of academics, scholars, and researchers: Megan Boler from the Ontario Institute for Studies in Education of the University of Toronto, Charles Ess who is at Drury University, Norwegian University of Science and Technology, Jim Garrison, Virginia Tech, Henry Giroux at McMaster University, Mimi Ito of the Annenberg Center at the University of Southern California, Cushla Kapitzke from the University of Queensland, Kinshuk who has recently joined Athabasca University, Penina Mlama of the University of Dar es Salaam, Nuria Oliver from Microsoft, K. Ann Renninger, Swarthmore College, and Ingvar Sigurgeirsson at the Iceland University of Education. This esteemed international group of scholars has supported us continuously in our efforts to launch the journal.

The aims of this journal is as follows:

Learning Inquiry is a refereed scholarly journal, devoted to establishing the area of "learning" as a focus for transdisciplinary study. The journal is a forum centered on learning that remains open to varied objects of inquiry, including machine, human, plant and animal learning as well as the processes of learning in business, government, and the professions, both in formal and informal environments. This journal is of importance to those interested in learning, understanding its contexts, and anticipating its future. The journal will also present special issues that identify the central areas of learning inquiry to provide focus for future research. Learning Inquiry strikes a balance between presenting innovative research and documenting current knowledge to foster a scholarly dialogue on learning that is independent of domain and methodological restrictions.

Learning Inquiry is intended to be expansive and transdisciplinary in scope. We want to involve researchers, practitioners, and others in the discussion of learning in the broadest contexts. In doing this we are trying to develop a place for inquiry into learning across the disciplines. We hope this new location will enable a sharing of understandings of learning that is theoretically informed and pragmatically rich. The articles in this issue illustrate that goal.

Our hope is that anyone with a basic literacy and a willingness to pursue the topic of learning and to invest their time and effort will find Learning Inquiry to be accessible and open to them, both as readers and contributors. Readers will find some materials in the journal more challenging than others, but the goal of being able to be read and understood by a general audience is at the forefront of our mission. However, in pursuing general accessibility in our arguments, we do not want to forego disciplinary perspectives that appeal to a narrower audience.

Recently, learning has been brought to the forefront in many countries around the globe though a push toward the learning sciences and a new investment in education 
in the scientific, technological, engineering, and medical fields. This signals a great future for learning, and the scientization of certain elements of learning will push the boundaries of our understanding, fertilizing the grounds of practice and theory development. We should not lose the broader foundation of learning though. The interpretavist, pragmatic, critical, and empiricist traditions come together to form a whole that we hope Learning Inquiry comes to represent. We want to resist the perspectivalism that arises in the disciplines and foster a conversation that includes the scientific, humanistic, and artistic practices that constitute learning in our everyday life.

The potentially rigid lines of the discourses in the disciplines and their perspectives are not the only obstacles toward promoting a new, global understanding of learning. Another obstacle is the tendency toward culturalism, regionalism, nationalism, and the governance of populations in regimes that accept those doctrines. The construction of similarities across human experience needs to be addressed, that is certain, but so does the construction of differences within and outside of these communities and populations. We cannot just accept the naturalization of both differences and similarities in the field of learning without realizing that sometimes the natural claims are, at least in part, normative claims. We realize the real power of differences amongst cultures upon learning, and think that these differences need to be understood if we are to understand learning. Through the journal, our goal is to aim for a global understanding of learning, which can be the basis for more understanding across disciplines, across cultural and geographic boundaries, and across the barriers that were built in the past.

Awareness of learning is often lost in the deluge of social experience that is our daily lives. We need to appreciate the ecologies and contexts of learning from its individual aspects to its collective or shared elements. What is learned, we must realize, might find a home in one mind, but it originates amongst and through many minds, and their creations. However, our tendency to anthropomorphize learning systems is also problematic. The things that learn in this world are as diverse as the world itself and may even be the world itself, depending on individual perspectives. It is not only humans, but also animals, machines, organizations, and ecologies that engage in learning. We want to be inclusive of all things that learn and invite submissions from all areas of learning.

For our first issue of Learning Inquiry, we invited a series of papers to be written on the topic of "the futures of learning." This special forum will both inaugurate the new journal, and lay the foundations for its growth, and call upon participants to explore the notion of "the futures of learning" through their own particular conceptual lens. Contributions from Gary Natriello, Erik De Corte, Helen Ruth Verran, Mark Warschauer, Stuart Moulthrop, Doug Kellner and Jeff Share, and Heinz Mandl and Katrin Winkler form a constellation of possibilities for inquiry into learning that will hopefully be further explicated as the lens of Learning Inquiry finds its focus.

Gary Natriello's paper, "Imagining, Seeking, Inventing: The Future of Learning and the Emerging Discovery Networks," starts off our foray into the futures of learning by weaving 12 trends that help to frame a perspective on the direction where learning is moving. He looks beyond institutions and disciplines in order to discuss diverse and contextualized locations that can include the professional and institutional, and trans-national. The paper considers the complex possibilities of learning that includes combinations of the human/machine matrix in more 
interactive, distributed, and biological configurations, leading to discovery networks for real world problems. Learning, in the future, is something that is both global in scope and predicated on individual negotiations between learners and educators.

In "Learning from Instruction: The Case of Mathematics," Erik De Corte situates his discussion of adaptive competence in the subject area of mathematics through an exploration of the kinds of learning and learning processes necessary to foster competence. The movement from teacher-directed learning to experiential and action-based learning he describes, seeks to engage all three approaches to learning. In order to embed traditional methods in a notion of learning, he describes "an active/constructive, cumulative, self-regulated, goal-directed, situated, collaborative, and individually different process of meaning construction and knowledge building."

Helen Verran's "Metaphysics and Learning: Method and Inquiry into Learning" explores learning while articulating the metaphysical basis of learning; drawing from her work with Yoruba children in Nigeria, she introduces the notion of 'ontics' as an enacted form of knowing. Verran suggests that seeing 'ontics' as enacted represents an opportunity to transcend 'pasts' and look to inquiry into learning as a form of "doing the world."

Mark Warschauer's contribution entitled "The Paradoxical Future of Digital Learning" takes up the assumptions of conventional wisdom regarding what digital technology has to offer in terms of the locations of learning, what can and cannot be learned, and the form that learning can take in emerging learning environments.

Stuart Moulthrop's "Learning, Change, and the Utopia of Play" challenges the techo-positivist notions that rejoice in the emerging global civilization. Moulthrop's contribution also challenges the value of identifying the field of literacy as a location for understanding media very distant from reading and writing, with video games being the extreme example. The paper suggests that seeing new forms of creative communication and expression in terms of traditional text-based literacy metaphors, with the concomitant understandings of content and authorship, can limit the pedagogical possibilities new media may afford.

Douglas Kellner and Jeff Share's paper "Critical Media Literacy is Not an Option" reminds us of the centrality of critical media literacy in an era of standardized testing and the increasing corporate influence into public education. The question is how it should be taught, not if it has a place in our learning institutions. For those invested in progressive pedagogical change, radical democracy, issues of gender, race, class, and power, Kellner and Share provide both conceptual and practical examples in their exploration of the intersections of media literacy, cultural studies, and critical pedagogy.

Finally, in "Implementation of Knowledge Management in Organizations," Mandl Heinz and Katrin Winkler present a case study-based model based on their explorations into how knowledge management often forgets to take learning into account when new ideas are implemented. The authors take up how organizations engage learning with the goal of revealing the basic conditions for the successful bringing together of how participants in the process of change learn about what they are expected to incorporate into their professional practice.

When we originally thought of the idea of a first issue with the theme, "The Futures of Learning," we contacted many people in many disciplines. Given people's prior commitments, we are immensely pleased at the quality of the contributions to this issue. We have in mind a second issue on the Futures of Learning that will, in part, respond to, and extend the positions of this issue, and hopefully introduce new Springer 
ideas. We would like to invite people interested in addressing the futures of learning from biological systems, to machine learning, to business environments, to economics, ecological, and other learning systems. The key issue of this journal is to explore the topic of learning and contribute to the research about that topic. We hope to build upon these themes and have a strong future constructing a new transdisciplinary field of learning. 